COMMISSION 41. HISTORY OF ASTRONOMY/HISTOIRE DE L'ASTRONOMIE

Report of Meetings, 15 and 16 August 1979

PRESIDENT: J. Dobrzycki

\title{
Business session
}

Silent tribute was paid to members lost by death since 1976, V.L. Chenakal, T. Przypkowski, V.V. Michkovitch and B. Sticker.

The Commission dealt with the election of its officers for the next term and with the admission of new members. In accord with the policy adopted in previous terms, the Commission sponsored the admission of several outstanding and professionally active consulting members to a full IAU membership.

A survey of the progress of various long term editorial projects was presented by J. Dobrzycki and J. Fleckenstein /editions of works of Copernicus, Kepler, Euler, Bernoulli/ and M. Hoskin/General History of Astronomy/. From M. Hoskin's report it appears that editorial work is most advanced on volume IV, dealing with the recent history of astronomy since inception of astrophysics, and on volume III /astronomers, instruments, stellar astronomy: XVII-XIX centuries/. These two volumes should be ready for processing by the publisher during 1980.

\section{Scientific session}

This session opened with the discourse by G. de Vaucouleurs on "The Early History of Astronomical Photography". Illustrated with examples demonstrating pioneer work in the consecutive photochemical teahniques applied to astronomy, the lecture outlined the main phases in the evolution of astrophotography.

John A. Eddy spoke on "Recent Progress in Archeoastronomy". He presented the possibilities and restrictions of astronomical evaluation of etnographic and archeological sources using three cases studies from American Precolumbian and Indian culture. Professional organization of the field was expanded by new periodical publications.

Susan McKenna-Lawlor presented a report on her studies on "Astronomical observations in Medieval Irish Chronicles". The survey of over thirty Gaelic and Latin chronicles is now in progress. Astronomical and climatic events, noted from 6 th century onwards, are analysed and put in context with local agricultural and military concerns.

It may be noted that similar surveys of cosmographical notes are advanced or in progress also for Italian and Polish sources.

"The Plenum Universe from Aristotle to Einstein" was the next subject, presented by Owen Gingerich. In a short synthetic review the speaker outlined the role of concepts like void and ether in the cosmology from ancient Greece to the times of Einstein.

Three short communications on history of Chinese astronomy followed. Dr. Y. Chang reported on the record of Halley's comet from 11th century $B C$. T. Kiang presented a report /by $H$. Siyi/ on a survey, now ready for publication, of astronomical data from local sources in ancient China /since 8 th century $A D /$. From this survey T. Kiang selected the subject of his communique on the supposed identification of Cygnus $X-1$ with a nova, recorded in Chinese /and Japanese/ records from 1408. 
Addenda to the report of the Commission

1. An exhibition of early astronomical photographs was set up during the IAU General Assembly. Authentic exhibits ranged from the early Harvard daguerotypes to dry-plate short focus survey photograms from Heidelberg. Exhibits were made available thanks to the courtesy of Harvard, Lick, Lund and Heidelberg observatories. The Merseyside County Museums, Liverpool, provided a series of panels with many reproductions of pioneer astronomical works. The co-operation of the contributing institutions is gratefully acknowledged. Special thanks are due to M. B. Drouin /Université de Montréal/for his efficient and instrumental help in setting up the exhibition.

2. Preservation and accessibility of various types of sources for history of astronomy is a highly topical problem, discussed at the 1976 Commission meeting. For written material one can name cases of satisfactory attention given to this matter by the Royal Greenwich Observatory, Herstmonceux, and the R.A.S. /the Herschel archives/. A growing problem is that of obsolete observatory equipment. Quite a number of big-sized instruments of historical importance become redundant and may, or have already to, be dismounted. It is hoped that in each case satisfactory documentation of the instrument will be preserved for possible future needs.

3. Information services of the Commission are continued. Shortly before the Montréal meeting Information circular No. 29 was distributed by the president, and No. 17 of the "Bibliography on books and papers on history of astronomy" /for 1976/ was issued at the Sternberg Astronomical Institute in Moscow.

4. The following, highly selective list of books published in 1976 - 1979 illustrates to some extent the main and topical fields of interest within history of astronomy. In general, perhaps the most penetrating research may be noted in history of medieval and Renaissance cosmology, the Islamic mathematical astronomy and, in a subject markedly distant in time, twentieth century astrophysics and cosmology. Established journals on history of science had the main share in the publication of research results.

Āryabhata, Āryabhatiya /critical edition of the texts and of its commentaries/, Delhi 1976

R. Berendzen, R. Hart, D. Seeley, Man Discovers the Galaxies, New York 1976

D.M. Clark, F.R. Stephenson, The historical supernovae, Oxford 1977

N. Copernicus, On the Revolutions /Complete works II/, Warsaw-Cracow 1978

F. Barone /ed./, Opere di Nicola Copernico, Torino 1979

A.M. Duncan /ed./, N.Copernicus, on the revolutions of heavenly spheres, London 1976

D.0. Edge, M.J. Mulkay, Astronomy Transformed. The Emergence of Radio Astronomy in Britain, N.York - London 1976

J. Meeus, H. Mucke, Canon of Lunar Eclipses -2002 to +2526, Wien 1979

R.R. Newton, The Crime of Claudius Ptolemy, Baltimore - London 1977

J. North, Richard of Wallingford, Oxford 1976

A.G. Davis Philip, D.H. DeVorkin, In Memory of Henry Russel/Historical part of IAU Symposium No. 80, The HR Diagram, The 100th Anniversary of H.N. Russell/, Albany 1977

K. Shukla, Aryabhata, Indian Mathematician and astronomer, Delhi 1976

D.J. Warner, The Sky Explored. Celestial Cartography 1500-1800, N.York Amsterdam 1979

P. Zambelli /ed./, Alberto Magno, Speculum Astronomiae, Pisa 1977. 